\title{
Crescimento inicial de Carica papaya sob irrigação com águas salinas em solo com biofertilizante bovino
}

\section{Initial growth of Carica papaya under irrigation with saline water in soil with bovine biofertilizer}

\author{
Francisco Oliveira Mesquita ${ }^{1 *}$; Rummenigge Macêdo Rodrigues ${ }^{2}$; Reinaldo \\ Ferreira Medeiros ${ }^{3}$; Lourival Ferreira Cavalcante ${ }^{4}$; Rafael Oliveira Batista ${ }^{5}$
}

\begin{abstract}
Resumo
A salinidade é considerada um dos principais entraves para agricultura em todo mundo, constituindose num dos fatores limitantes ao crescimento, desenvolvimento das plantas, produtividade agrícola e depauperamento do solo. Nesse sentido, um experimento foi desenvolvido no período de Outubro de 2009 a Fevereiro de 2010, em ambiente telado, no município de Areia - PB, para avaliar a influência da salinidade da água de irrigação no crescimento do mamão Havaí em substrato não salino com biofertilizante rico. O substrato utilizado foi o material dos primeiros $0,10 \mathrm{~m}$ de um NEOSSOLO REGOLITICO não salino. O delineamento experimental foi inteiramente casualizado em esquema fatorial $5 \times 2$, referente aos valores de condutividade elétrica da água de irrigação: 0,$5 ; 1,0 ; 2,0 ; 3,0$ e 4,0 dS m$~^{-1}$, em solo sem e com biofertilizante líquido, com seis repetições. O biofertilizante rico, depois de diluído em água não salina $\left(0,5 \mathrm{dS} \mathrm{m}^{-1}\right)$ na razão de 1:1 foi aplicado uma única vez, dois dias antes da semeadura, em nível de $10 \%$ do volume do substrato. O aumento da salinidade da água de irrigação provocou perdas sobre todas as variáveis avaliadas nas plantas, mas com menor intensidade nos tratamentos com biofertilizante.
\end{abstract}

Palavras-chave: Mudas de mamão havaí, insumo orgânico, salinidade

\begin{abstract}
The salinity is considered the major constraint to agriculture worldwide, constituting a limiting factor to growth, plant development, agricultural productivity and soil deterioration. In this direction an experiment was carried out during the period October/2009 to February/2010, in greenhouse conditions in Areia county, Paraiba State, PB, Brazil, in order to evaluate the effects of water saline on initial growth of papaya Hawaii in non-saline substrate with bovine rich biofertilizer. The substrate was material of the first $0.10 \mathrm{~m}$ of a Regolitic Entisol non saline. The treatments were distributed in completely randomized in six replication using the factorial design $5 \times 2$, corresponding to levels of irrigation water saline: 0.5 ; $1.0 ; 2.0 ; 3.0$ and $4.0 \mathrm{dS} \mathrm{m}^{-1}$, in soil without and with rich biofertilizer applied to soil in liquid form one time two days before seed sowing, at level of $10 \%$ of the substrate volume. The increment of salinity water irrigation inhibited alls variables studied in papaya's plants, but with less range in treatments with bovine biofertilizer.
\end{abstract}

Key words: Seedlings of hawaii papaya, organic input, sanility

\footnotetext{
${ }^{1}$ Eng. ${ }^{\circ}$ Agro ${ }^{\circ}$ Doutorando da Universidade Federal Rural do Semi-Árido, UFERSA, Mossoró, RN. E-mail: mesquitaagro@yahoo. com.br

${ }^{2}$ Centro de Ciências Agrárias/CCA, Universidade Federal da Paraíba, UFPB. E-mail: rummenigge.mr@gmail.com

${ }^{3}$ Eng. ${ }^{\circ}$ Agr ${ }^{\circ}$, Mestre em Manejo de Solo e Água, Doutorando do PPGCS/CCA/UFPB, Areia, PB. E-mail: medeiros_rf@hotmail.com

${ }^{4}$ Prof. Dr. Dept ${ }^{\circ}$ de Solos e Engenharia Rural, CCA/UFPB, Areia, PB. E-mail:lofeca@cca.com.br

5 Prof. Adjunto II da UFERSA, Mossoró, RN.

* Autor para correspondência
} 


\section{Introdução}

A produção de mudas no Estado da Paraíba evidencia o crescimento da cultura do mamoeiro. A Paraíba destaca-se com a terceira maior produção do Nordeste e a $4^{\mathrm{a}}$ maior do país (ANUÁRIO BRASILEIRO DE FRUTICULTURA, 2010). Os municípios paraibanos de Mamanguape e Santa Rita, localizados na Zona da Mata Paraibana, detém 41,5 e $18,7 \%$, respectivamente, da safra desse fruto. A produção do município de Mamanguape é considerada uma das mais importantes, chegando a ocupar em 2003 o $19^{\circ}$ lugar dos principais municípios produtores de mamão do País (IBGE, 2004; BRITO NETO et al., 2011).

A fase de produção de mudas assume grande importância, pois, não se deve utilizar adubos químicos de alta solubilidade e concentração na composição dos substratos (ARAÚJO NETO et al., 2006). A produção de mudas constitui-se uma importante tecnologia no processo produtivo e necessita de conhecimentos para a transição do uso de substratos comerciais, com agroquímicos e de alto custo, para substratos com adubos orgânicos, de baixo custo e de fácil preparação (SILVA et al., 2006; MORAIS et al., 2010).

Trata-se de uma cultura considerada moderadamente tolerante à salinidade, isso significa que suporta níveis de condutividade elétrica do extrato de saturação do solo entre 3 e $6 \mathrm{dS} \mathrm{m}^{-1}$ sem inibição do crescimento e da sua capacidade produtiva (AYERS; WESTCOT, 1999). Embora, de modo geral, haja controvérsias quanto à tolerância das mudas de mamão aos efeitos dos sais. Apesar da maior tolerância aos sais, em relação às frutíferas como bananeira, goiabeira e gravioleira que são mais sensíveis, o cultivo do mamoeiro irrigado nas áreas semiáridas brasileiras tem provocado aumento da concentração salina no solo tanto em função da elevada temperatura do ar como pelo elevado conteúdo salino das águas. Essa inconveniência resulta na inibição do crescimento em altura, diâmetro do caule, área foliar, acúmulo de biomassa e produção das frutíferas, em geral, inclusive do mamoeiro (CAVALCANTE; CAVALCANTE, 2006). Uma vez que esses locais são potencialmente tendenciosos a provocar o acúmulo de sais e sódio (ARDAHANLIOGLU et al., 2003), interferindo no crescimento e desenvolvimento das plantas (TAIZ; ZEIGER, 2009), além de afetar a agregação e a estrutura do solo.

$\mathrm{O}$ acúmulo de $\mathrm{Na}^{+}$e $\mathrm{Cl}^{-}$, de forma isolada ou associada, em tecidos vegetais resultam em toxicidade iônica devido a intensas mudanças nas relações $\mathrm{Na}^{+} / \mathrm{K}^{+}, \mathrm{Na}^{+} / \mathrm{Ca}^{+2}$ e $\mathrm{Cl}^{-} / \mathrm{NO}_{3}^{-}$, provocando quedas de rendimento e, até mesmo, morte das plantas (FERREIRA et al., 2006; FERREIRASILVA et al., 2008).

Dentre as fontes orgânicas, o biofertilizante rico, que é produzido por meio da fermentação metanogênica de partes iguais de esterco fresco bovino e água, acrescido de gesso agrícola, leite e melaço (SANTOS; AKIBA, 1996; LEITE et al., 2010), tem exercido efeitos positivos na melhoria da estrutura física do solo (SHETEAWI; TAWFIK, 2007), germinação das sementes e crescimento de plantas em solos não salinos sob irrigação com águas de salinidade crescente. Resultados de Sousa et al. (2008), Carlesso et al. (2009), Campos et al. (2009), Cavalcante et al. (2010a) e Medeiros et al. (2011) revelam superioridade estatística da emergência e crescimento de plântulas de maracujazeiro amarelo (Passiflora edulis f. flavicarpa Deg), mamoeiro (carica papaya L.), mamoneira (Ricinus comunis), de goiabeira (Psidium guajava) e tomateiro cereja (Licopersicon pimpinellifolium L) em solo com o insumo orgânico irrigado com águas salinas, em relação ao solo sem biofertilizante.

As informações sobre a formação de mudas e o crescimento inicial do mamoeiro cultivado sob irrigação nas condições do semiárido nordestino são escassas. Considerando a importância econômica do mamoeiro para a economia brasileira e o aumento significativo das áreas plantadas irrigadas no Nordeste, o objetivo desse trabalho foi estudar 
o efeito da salinidade da água de irrigação sobre a formação de mudas de mamão Havaí em substrato com biofertilizante bovino.

\section{Material e Métodos}

Um experimento foi realizado no período de Outubro de 2009 a fevereiro de 2010, em abrigo telado do Departamento de Solos e Engenharia Rural da Universidade Federal da Paraíba, na cidade de Areia, PB, com latitude $6^{\circ} 58^{\prime}$ S, longitude $35^{\circ} 41^{\prime}$ $\mathrm{W}$ e altitude de $575 \mathrm{~m}$. O clima da região, segundo a classificação de Köppen-Geiger, é do tipo As' (quente e úmido), com estação chuvosa no período de março a julho e precipitação pluviométrica média anual de $1.200 \mathrm{~mm}$. A temperatura média do ar é de $23{ }^{\circ} \mathrm{C}$, apresentando valor elevado no mês de fevereiro $\left(25,7{ }^{\circ} \mathrm{C}\right)$ e mais ameno no mês de julho $\left(21,6{ }^{\circ} \mathrm{C}\right)$.

A temperatura média no período de realização do experimento no mês mais quente situou-se em torno de $32,35{ }^{\circ} \mathrm{C}$ fora e $44,91^{\circ} \mathrm{C}$ no interior do abrigo telado; já no mês mais frio, os valores variaram de $27,91{ }^{\circ} \mathrm{C}$ fora e $30,68^{\circ} \mathrm{C}$ dentro do ambiente telado, com umidade relativa do ar no mês mais quente de $57 \%$ fora e $48 \%$ dentro do ambiente telado; no mês mais frio $83 \%$ fora e $58 \%$ dentro do abrigo telado.

Os tratamentos foram distribuídos em delineamento inteiramente casualizado, com seis repetições, em arranjo fatorial 5 × 2 referente aos níveis crescentes de salinidade da água de irrigação: 0,$5 ; 1,0 ; 2,0 ; 3,0$ e 4,0 dS m$~^{-1}$, em solo sem e com biofertilizante. Os níveis salinos das águas de irrigação foram preparados a partir da diluição de uma água de barragem fortemente salina $(\mathrm{CEa}=$ $12,4 \mathrm{dS} \mathrm{m}^{-1}$ ) com água não salina de $0,5 \mathrm{dS} \mathrm{m}^{-1}$ (MESQUITA et al., 2010). Como substrato foi utilizado um NEOSSOLO REGOLITICO não salino (SANTOS et al., 2006) coletado na camada de 0-0,10 m. Amostras do solo foram passadas em peneira com malha de $2 \mathrm{~mm}$ e analisadas quanto aos atributos químicos e físicos (EMBRAPA, 1997) e de salinidade (RICHARDS, 1954), indicados na (Tabela 1). As unidades experimentais foram compostas por bolsas de polietileno preto com capacidade para 3,5 litros acondicionadas com $3 \mathrm{~L}$ do material de solo.

O biofertilizante rico foi obtido a partir da fermentação metanogênica de esterco fresco bovino misturado com água não clorada e não salina, na proporção de 1:1 (100 L de cada componente) em recipiente com capacidade para 240 litros, acrescido de $4 \mathrm{~L}$ de melaço, $8 \mathrm{~L}$ de leite bovino e $4 \mathrm{~kg}$ de gesso agrícola, fornecidos semanalmente nos valores de 1:2:1. Para a manutenção de cada sistema hermeticamente fechado, foi conectado uma extremidades de uma mangueira de $4 \mathrm{~mm}$ de diâmetro na base superior do biodigestor e a outra imersa em um recipiente com água. O gesso continha $68 \%$ de solubilidade em água, $21 \%$ de umidade, $26 \%$ de $\mathrm{CaO}$ e 14 a $17 \%$ de S (LEITE et al., 2010); $100 \%$ de suas partículas passaram em peneiras com $2 \mathrm{~mm}, 70 \%$ em peneiras com diâmetro de $0,84 \mathrm{~mm}$ e $50 \%$ em peneira com diâmetro de $0,30 \mathrm{~mm}$. Além disso, teve-se o cuidado de reservar um espaço de $20 \%$ da capacidade do recipiente para facilitar a liberação dos gases produzidos no processo fermentativo. Dois dias antes da semeadura, o biofertilizante foi diluído em água na proporção 1:1 e aplicado em volume equivalente a $10 \%$ do volume do substrato $(300 \mathrm{~mL})$. Por ser aplicado na forma líquida, o biofertilizante foi avaliado como se fosse água para irrigação e apresentou os seguintes valores: $\mathrm{Ca}^{2+}=22,65, \mathrm{Mg}^{2+}=10,55, \mathrm{Na}^{+}=8,21, \mathrm{~K}^{+}$ $=20,48, \mathrm{Cl}^{-}=31,50 ; \mathrm{HCO}_{3}=9,80 \mathrm{mmol}_{\mathrm{c}} \mathrm{L}^{-1}$ e $\mathrm{SO}$ condutividade elétrica a $25{ }^{\circ} \mathrm{C}=6,17 \mathrm{dS} \mathrm{m}^{-1}$ e $\mathrm{pH}=$ 6,77 (RICHARDS, 1954). 
Tabela 1. Caracterização física e química do solo quanto à fertilidade e salinidade do solo na camada de $0-10 \mathrm{~cm}$. CCA/UFPB, Areia, PB, Brasil, 2010.

\begin{tabular}{|c|c|c|c|c|c|}
\hline Atributos físicos & Valor & Atributos de fertilidade & Valor & Atributos de salinidade & Valor \\
\hline Ds $\left(\mathrm{g} \mathrm{cm}^{-3}\right)$ & 1,54 & pH em água $(1: 2,5)$ & 6,59 & CEes $\left(\mathrm{dS} \mathrm{m}^{-1}\right)$ & 0,79 \\
\hline $\mathrm{Dp}\left(\mathrm{g} \mathrm{cm}^{-3}\right)$ & 2,66 & $\mathrm{MO}\left(\mathrm{g} \mathrm{Kg}^{-1}\right)$ & 11,31 & $\mathrm{pH}$ & 6,71 \\
\hline $\operatorname{Pt}\left(\mathrm{m}^{3} \mathrm{~m}^{-3}\right)$ & 0,42 & $\mathrm{P}\left(\mathrm{mg} \mathrm{dm^{-3 }}\right)$ & 25,41 & $\mathrm{Ca}^{2+}\left(\mathrm{mmol}_{\mathrm{c}} \mathrm{L}^{-1}\right)$ & 1,92 \\
\hline Areia $\left(\mathrm{g} \mathrm{kg}^{-1}\right)$ & 858 & $\mathrm{~K}^{+}\left(\mathrm{mg} \mathrm{dm} \mathrm{m}^{-3}\right)$ & 115 & $\mathrm{Mg}^{2+}\left(\operatorname{mmol}_{\mathrm{c}} \mathrm{L}^{-1}\right)$ & 1,21 \\
\hline Silte $\left(\mathrm{g} \mathrm{kg}^{-1}\right)$ & 59 & $\mathrm{Ca}^{+2}\left(\mathrm{cmol}_{\mathrm{c}} \mathrm{dm}^{-3}\right)$ & 1,82 & $\mathrm{Na}^{+}\left(\mathrm{mmol} \mathrm{L}^{-1}\right)$ & 3,46 \\
\hline Argila $\left(\mathrm{g} \mathrm{kg}^{-1}\right)$ & 83 & $\mathrm{Mg}^{+2}\left(\mathrm{cmol}_{\mathrm{c}} \mathrm{dm}^{-3}\right)$ & 0,49 & $\mathrm{~K}^{+}\left(\mathrm{mmol} \mathrm{L}^{-1}\right)$ & 1,08 \\
\hline Ada $\left(\mathrm{g} \mathrm{kg}^{-1}\right)$ & 13 & $\mathrm{Na}^{+}\left(\mathrm{cmol}_{\mathrm{c}} \mathrm{dm}^{-3}\right)$ & 0,21 & $\mathrm{Cl}^{-}\left(\mathrm{mmol}_{\mathrm{c}} \mathrm{L}^{-1}\right)$ & 5,17 \\
\hline GF $(\%)$ & 84,34 & $\mathrm{H}^{+}+\mathrm{Al}^{+3}\left(\mathrm{cmol}_{\mathrm{c}} \mathrm{dm}^{-3}\right)$ & 1,16 & $\mathrm{CO}_{3}^{2-}\left(\mathrm{mmol}_{\mathrm{c}} \mathrm{L}^{-1}\right)$ & - \\
\hline ID $(\%)$ & 15,66 & $\mathrm{Al}^{+3}\left(\mathrm{cmol}_{\mathrm{c}} \mathrm{dm}^{-3}\right)$ & 0,00 & $\mathrm{HCO}_{3}^{-}\left(\mathrm{mmol}_{\mathrm{c}} \mathrm{L}^{-1}\right)$ & 1,51 \\
\hline $\mathrm{U}_{\mathrm{cc}}\left(\mathrm{g} \mathrm{kg}^{-1}\right)$ & 10,84 & $\mathrm{SB}\left(\mathrm{cmol}_{\mathrm{c}} \mathrm{dm}^{-3}\right)$ & 2,81 & $\mathrm{SO}_{4}{ }^{2-}\left(\mathrm{mmol}_{\mathrm{c}}^{\mathrm{c}} \mathrm{L}^{-1}\right)$ & 0,98 \\
\hline $\mathrm{U}_{\mathrm{pmp}}\left(\mathrm{g} \mathrm{kg}^{-1}\right)$ & 4,54 & CTC $\left(\mathrm{cmol}_{\mathrm{c}} \mathrm{dm}^{-3}\right)$ & 3,97 & RAS $\left(\mathrm{mmol} \mathrm{L}^{-1}\right)^{1 / 2}$ & 2,75 \\
\hline $\operatorname{Ad}\left(\mathrm{g} \mathrm{kg}^{-1}\right)$ & 5,30 & V (\%) & 70,78 & $\operatorname{PST}(\%)$ & 5,28 \\
\hline
\end{tabular}

$\mathrm{Ds}=$ Densidade do solo; $\mathrm{Dp}=$ Densidade de partícula; $\mathrm{Pt}=$ Porosidade total $; \mathrm{Ada}=$ Argila dispersa em água; $\mathrm{GF}=\mathrm{Grau}$ de floculação; $\mathrm{ID}=$ Índice de dispersão; $\mathrm{U}_{\mathrm{cc}}$ e $\mathrm{U}_{\mathrm{pmp}}=$ respectivamente umidade do solo às tensões de $-0,01 \mathrm{e}-1,5 \mathrm{Mpa}$; $\mathrm{Ad}=$ Águas disponível; $\mathrm{MO}=$ Matéria orgânica; $\mathrm{SB}=$ Soma de bases $\left(\mathrm{Na}^{+}+\mathrm{K}^{+}+\mathrm{Ca}^{2+}+\mathrm{Mg}^{2+}\right)$; CTC $=$ Capacidade de troca catiônica $=\mathrm{SB}+$ $\left(\mathrm{H}^{+}+\mathrm{Al}^{1+}\right) ; \mathrm{V} \%$ = Valor de saturação por bases $(100 \mathrm{x} \mathrm{SB} / \mathrm{CTC})$; CEes = Condutividade elétrica do extrato de saturação; RAS = Relação de adsorção de sódio $=\mathrm{Na}^{+} \mathrm{x}\left[\left(\mathrm{Ca}^{2+}+\mathrm{Mg}^{2+}\right) / 2\right]^{-1 / 2} ; \mathrm{PST}=$ Percentagem de sódio trocável $=100 \mathrm{x}\left(\mathrm{Na}^{+} / \mathrm{CTC}\right)$.

Fonte: Elaboração dos autores.

Em cada unidade experimental foram semeadas quatro sementes de mamão Havaí (Licopersicon pimpinellifolium L.) com viabilidade de $87 \%$. Aos 35 dias após a emergência, foi realizado o desbaste das plantas deixando-se apenas a mais vigorosa. A irrigação foi feita com base no processo de pesagem, fornecendo-se diariamente o volume de cada água correspondente a evapotranspirada, de modo a elevar o solo ao nível de capacidade de campo. A cada 30 dias foi obtida a altura de plantas e diâmetro do caule. Ao final do experimento obtevese a massa seca da parte aérea, de raiz, massa seca total, diâmetro e comprimento da raiz, área foliar e radicular. A altura de plantas foi determinada pela medição vertical das plantas utilizando uma régua milimetrada, o diâmetro do caule e da raiz foi medido com paquímetro digital e o material vegetal seco (raiz+folhas) foi obtido após secagem em estufa com circulação de ar forçada à temperatura de $65^{\circ} \mathrm{C}$ até massa constante. As áreas foliar e radicular foram quantificadas, a partir de imagens fotográficas obtidas com câmera fotográfica digital SONY DSC W-55, 7.2 megapixels e processadas pelo software Sigma Scan Pro 5.0 Demo. A massa seca das raízes e parte aérea (caules mais folhas) foi obtida por pesagem em balança analítica após secagem em estufa com circulação de ar à temperatura de $65^{\circ}$ até massa constante.

O crescimento das mudas foi computado a partir dos dados de altura de plantas (AP), diâmetro de caule (DC), diâmetro da raiz (DR), área foliar (AF), área radicular (AR), massa seca de parte aérea (MSPA), massa seca de raiz (MSR) e massa seca total (MST), bem como, o pH do solo e condutividade elétrica do extrato de saturação (CEes).

Os dados foram submetidos à análise de variância pelo teste "F" e regressão polinomial para os níveis de salinidade (BANZATTO; KRONKA, 2008). Para o processamento dos dados foi utilizado o programa SAS (SAS INSTITUTE INC, 2003).

\section{Resultados e Discussão}

A condutividade elétrica do extrato de saturação (CEes) foi influenciada significativamente pela interação salinidade da água $\mathrm{x}$ biofertilizante expressando superioridade estatística nos 
tratamentos com biofertilizante bovino, como indicado na Figura 1.

No solo com biofertilizante a CEes foi elevada de $1,64 \mathrm{dS} \mathrm{m}^{-1}$ para até $5,77 \mathrm{dS} \mathrm{m} \mathrm{m}^{-1}$ com o aumento da condutividade elétrica da água. Comparativamente ao tratamento sem biofertilizante, isso corresponde a um incremento pouco maior que $6 \%$. O caráter salino do substrato foi elevado de não salino (CEes $\left.<2 \mathrm{dS} \mathrm{m}^{-1}\right)$ para moderadamente salino $(4<\mathrm{CEes}<$ $8 \mathrm{dS} \mathrm{m}^{-1}$ ), condição que compromete o desempenho das culturas sensíveis, para até fortemente salino, onde apenas as culturas mais tolerantes apresentam crescimento e rendimento satisfatórios (RICHARDS, 1954; EL-HENDAWY et al., 2005).

Figura 1. Condutividade elétrica do estrato de saturação em função da salinidade da água no solo sem (---) e com (-) biofertilizante rico das mudas de mamão Havaí. CCA/UFPB, Areia, Brasil-2011.

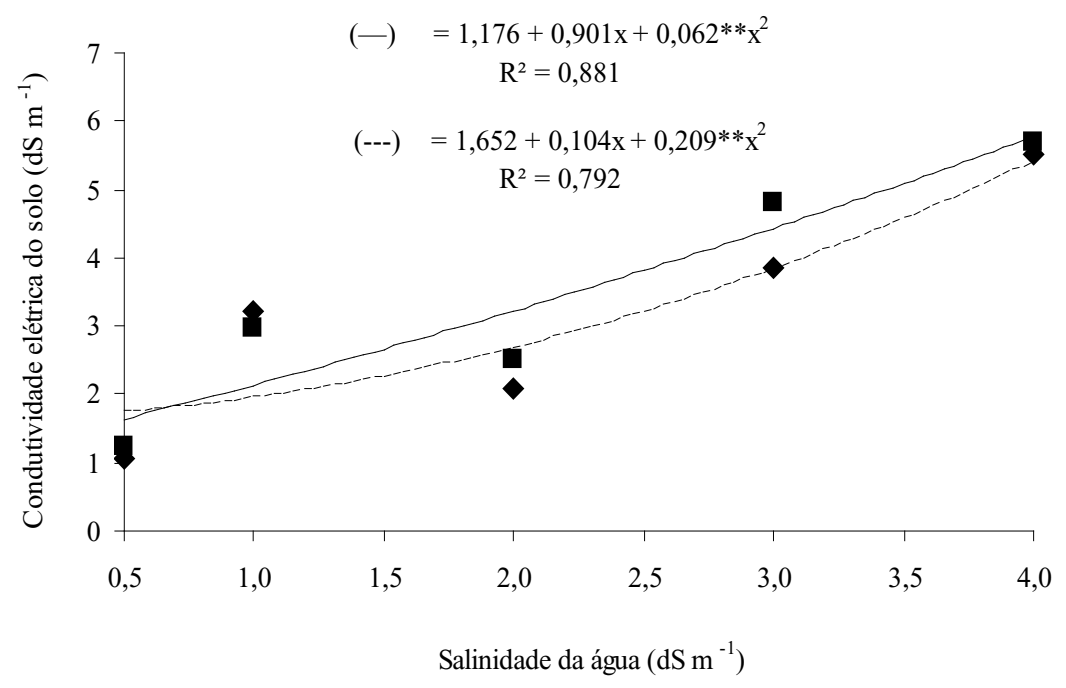

Fonte: Elaboração dos autores.

A superioridade dos níveis salinos no solo tratado com biofertilizante em relação ao solo sem, é devido à elevada condutividade elétrica deste insumo, o qual apresentava, no momento de sua aplicação,

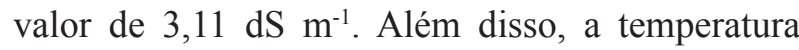
média no local de execução do experimento também pode ter contribuído para esse incremento, onde apresentou alta demanda evaporativa com valores médios de $44,91^{\circ} \mathrm{C}$ no interior da casa de vegetação. De fato, esses resultados foram coletados no período de alta demanda evaporativa, ocasionando proporcionalmente aumento da salinidade do solo, além do incremento do teor salino das águas, com valores médios no ponto de máximo $32,35^{\circ} \mathrm{C}$ fora e $44,91{ }^{\circ} \mathrm{C}$ dentro da casa de vegetação. Pode ser atribuído também à baixa umidade relativa do ar, com valores médios no ponto de máximo entre $57 \%$ fora e $62 \%$ dentro da casa de vegetação. A elevada temperatura promove evaporação e transpiração das plantas, resultando em maior acúmulo de sais no solo (CAVALCANTE; CAVALCANTE, 2006).

Ao considerar que a relação das plantas com a salinidade é aferida, segundo Maas e Hoffmann (1977), pelo contato do sistema radicular com o meio salino, e que o mamoeiro é uma cultura que apresenta caráter moderadamente tolerante aos efeitos dos sais em águas de restrição moderadas, isto é, $0,77<\mathrm{CEa}<3,0 \mathrm{dS} \mathrm{m} \mathrm{m}^{-1}$ (AYERS; WESTCOT, 1999) ou severas ( $\left.\mathrm{CEa}>4,0 \mathrm{dS} \mathrm{m}{ }^{-1}\right)$ a cultura pode sofrer danos severos e irreversíveis, o que indubitavelmente pode ocorrer perdas na 
germinação e redução no crescimento da planta (YURTSEVEN; KESMEZ; ÜNLÜKARA, 2005). Nos tratamentos sem biofertilizante, a irrigação com águas de composição salina de 0,5 a 4,0 dS m${ }^{-1}$ elevou o caráter salino do solo que era de $0,79 \mathrm{dS}$ $\mathrm{m}^{-1}$, antes da aplicação dos tratamentos (Tabela 1), para até $5,41 \mathrm{dS} \mathrm{m}^{-1}$ no final do experimento.

A condutividade elétrica do solo estudada por Cavalcante et al. (2010a) e Freire et al. (2011) ao avaliarem o desenvolvimento inicial de mudas de mamoeiro (Carica papaya L.) e maracujazeiro amarelo (Passiflora edullis f. Flavicarpa Deg.) obtiveram valores conflitantes de até $11,04 \mathrm{dS} \mathrm{m}^{-1}$ no substrato irrigadas com diferentes níveis e fontes de águas. No entanto, a irrigação das plantas de maracujazeiro amarelo com água de maior nível salino $\left(4,5 \mathrm{dS} \mathrm{m}^{-1}\right)$ elevou a condutividade elétrica média da solução lixiviada em até $2,2 \mathrm{dS} \mathrm{m}^{-1}$. Esse comportamento não só ocorre na cultura do mamoeiro como também em maracujazeiro amarelo Mesquita et al. (2010) e tomate cereja, conforme
Medeiros et al. (2011), sob condições semelhantes de salinidade.

Com base na (Figura 2), os resultados da altura das plantas de mamoeiro, não exerceram efeitos significativos para efeito da interação salinidade $\mathrm{x}$ biofertilizante. No entanto, as plantas de mamoeiro conseguiram obter valores de 8,41 e $27 \mathrm{~cm}$ no substrato sem e com biofertilizante rico. Tal fato mostra que o biofertilizante exerce efeitos positivos sobre o crescimento das plantas, devido às melhorias físicas e químicas do substrato, promovida pelas substâncias húmicas, resultando em maior ajustamento osmótico(LIANGetal., 2005). Constatase que o insumo orgânico promoveu um aumento de $221,0 \%$ no seu crescimento em altura equiparadas aos tratamentos que não receberam o biofertilizante. De fato, esse comportamento está coerente com Mahmoud e Mohamed (2008) ao avaliarem efeito da salinidade na cultura do trigo, onde os mesmos verificaram resposta positiva das plantas à salinidade com a utilização de biofertilizante.

Figura 2. Altura das mudas de mamão Havaí em substrato na ausência (1) e presença (2) de biofertilizante rico. Médias seguidas por letras iguais na coluna (maiúscula para salinidade e minúscula para biofertilizante) não diferem estatisticamente pelo teste Tukey a 5\% de probabilidade. CCA/UFPB, Areia, Brasil-2011.

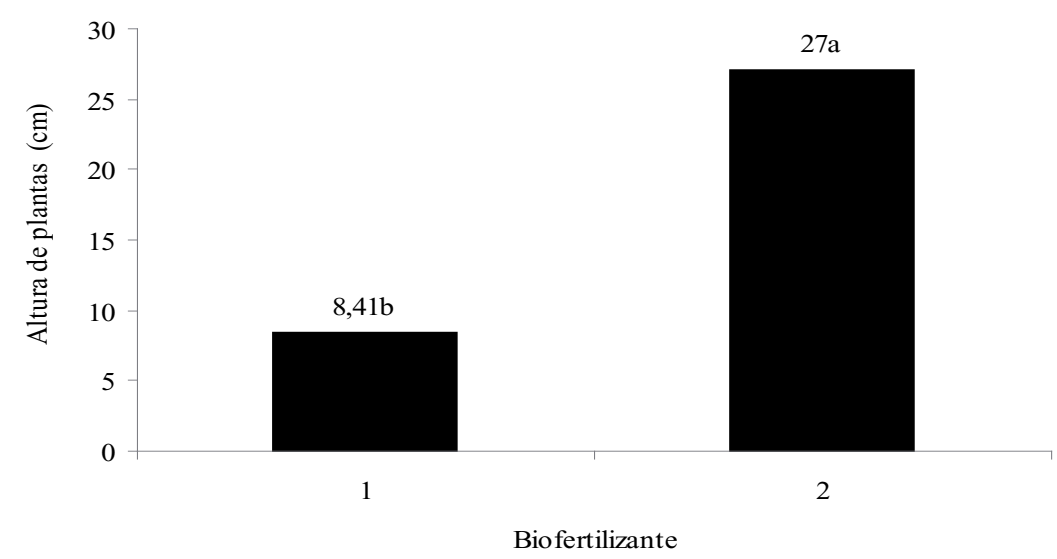

Fonte: Elaboração dos autores. 
O comportamento dos dados está bem abaixo dos registrados por Santos et al. (2007) ao avaliarem a produção de mudas de mamão cv. 'Sunrise solo' em diferentes substratos orgânicos chegando a valores próximos de $36 \mathrm{~cm}$. Porém, inferiores aos verificados por Cavalcante et al. (2010a) ao estudarem fontes e níveis da salinidade da água sobre a formação de mudas de mamoeiro, no qual, obtiveram valores de $13 \mathrm{~cm}$ no nível de salinidade de $4 \mathrm{dS} \mathrm{m}^{-1}$ e por Santos et al. (2010) ao estudarem formação de mudas de mamoeiro Havaí irrigado com águas salinas e com biofertilizante atingindo valor próximo de $18 \mathrm{~cm}$.

$\mathrm{Na}$ (Figura 3) o biofertilizante estimulou o aumento do diâmetro das plantas em até
11,24 $\mathrm{mm}$ na salinidade máxima estimada de $2,13 \mathrm{dS} \mathrm{m}^{-1}$. Esse valor difere estatisticamente do valor mínimo de $4,45 \mathrm{~mm}$ das plantas irrigadas com água de $0,5 \mathrm{dS} \mathrm{m}^{-1}$ no solo sem o insumo orgânico. Percentualmente as mudas de mamão Havaí tratadas com biofertilizante superou em até $152,58 \%$ o crescimento do diâmetro caulinar das plantas equiparada aos substratos sem o composto orgânico.

Essa situação reporta que o mamoeiro, assim como muitas outras plantas moderadamente tolerantes aos efeitos salinos (AYERS; WESTCOT, 1999) responde diferenciadamente à composição iônica da água de irrigação para um mesmo nível de condutividade elétrica.

Figura 3. Diâmetro do caule das mudas de mamoeiro para efeito da salinidade da água no solo sem (---) e com (-) biofertilizante rico. CCA/UFPB, Areia, Brasil-2011.

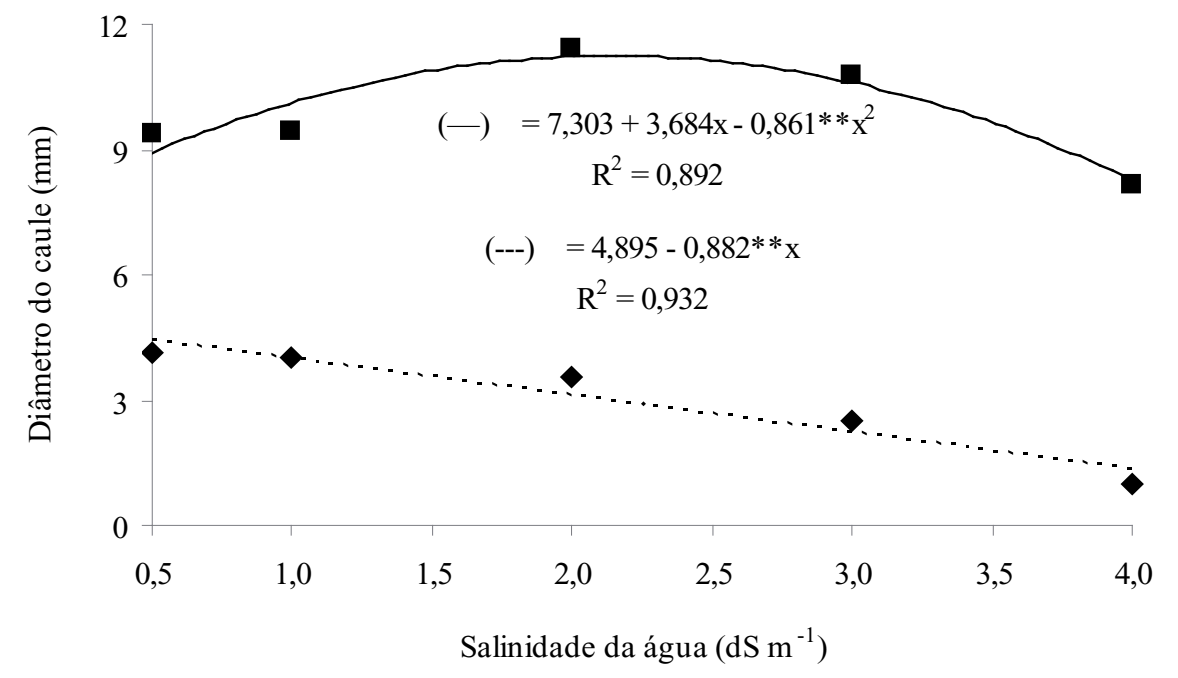

Fonte: Elaboração dos autores.

O comportamento dos dados está coerente com Cavalcante et al. (2010b) ao constatarem que o biofertilizante promoveu maior crescimento de mudas de goiabeira (Psidium guajava) sob irrigação com águas salinas. Porém, são além dos maiores valores obtidos por Cavalcante et al. (2010a) ao avaliarem o diâmetro do caule de plantas de mamão aos 60 dias após a germinação em função dos níveis e fontes de sais da água de irrigação. Estes autores, conseguiram obter maior valor de $8,64 \mathrm{~mm}$ no nível salino estimado de $1,89 \mathrm{dS} \mathrm{m}^{-1}$. Luna Souto et al. (2010) ao avaliarem o diâmetro do caule de plantas de mamão Havaí irrigado com águas salinas no substrato sem e com biofertilizante, constataram que aos 90 dias após a emergência, as plântulas atingiram seu valor médio de 5,74 mm. Estão 
também bem acima dos encontrados por Rodrigues et al. (2010) ao avaliarem o diâmetro do caule das mudas de mamão Havaí tratados em função da salinidade da água com biofertilizante conseguindo obter valor máximo de 11,26 mm no maior teor salino da água de irrigação de $2,27 \mathrm{dS} \mathrm{m}^{-1}$.

O diâmetro da raiz principal das plantas de mamão Havaí foi influenciado significativamente pela interação salinidade da água $\mathrm{x}$ biofertilizante e expressa superioridade nos tratamentos com biofertilizante (Figura 4). O diâmetro da raiz das plantas de mamão no substrato aumentou de 3,71 $\mathrm{mm}$ no caráter salino $\left(1,21 \mathrm{dS} \mathrm{m}^{-1}\right)$ atingindo o maior valor de 11,09 $\mathrm{mm}$ na condutividade elétrica estimada de $2,11 \mathrm{dS} \mathrm{m}^{-1}$, isto é, no solo sem e com biofertilizante rico aplicado uma semana antes da germinação (Figura 4). Com base na referida Figura, a irrigação com água de teor salino maior que $2,11 \mathrm{dS} \mathrm{m}^{-1}$ provocou estresse e inibiu o desenvolvimento do diâmetro radicular das mudas. Ao comparar os resultados das plantas de mamoeiro no mesmo substrato com biofertilizante, se observa que apesar da superioridade, após a emergência, as plântulas sofreram declínio 5,38 $\mathrm{mm}$ para cada aumento unitário da condutividade elétrica da água de irrigação.

Figura 4. Diâmetro da raiz das mudas de mamoeiro para efeito da salinidade da água no solo sem (---) e com (-) biofertilizante rico. CCA/UFPB, Areia, Brasil-2011.

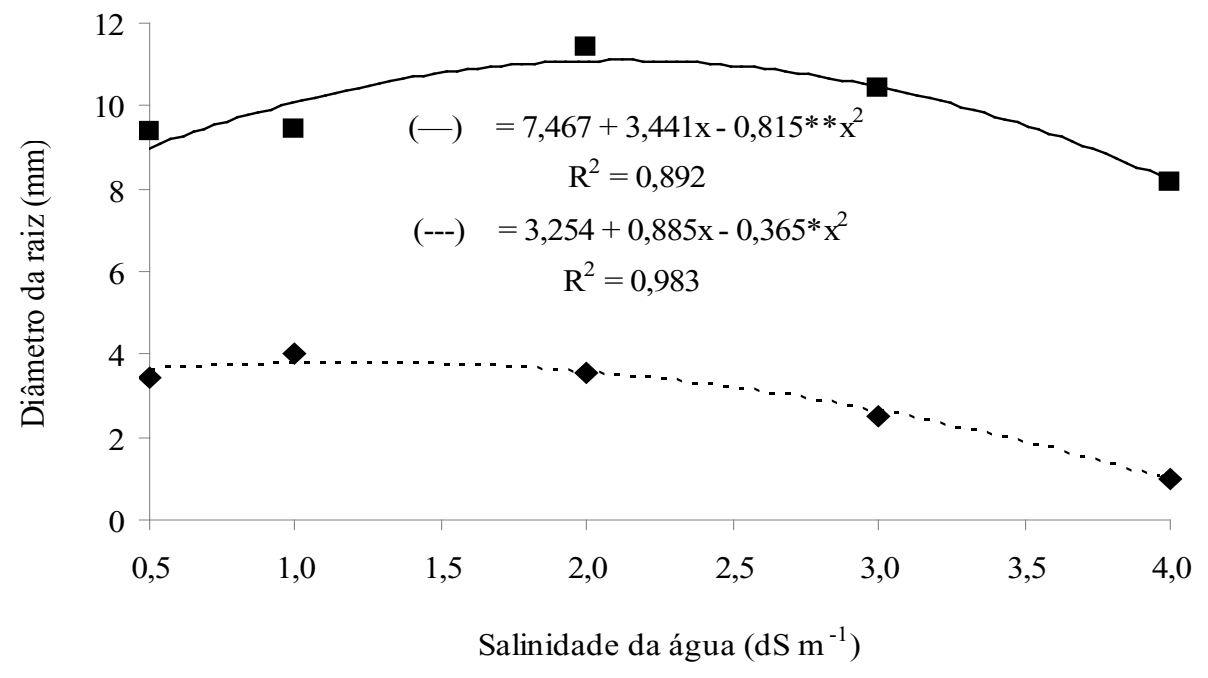

Fonte: Elaboração dos autores.

Com relação ao declínio no diâmetro de raiz principal nos tratamentos sem biofertilizante, Munns e Tester (2008) relataram que a inibição no crescimento do sistema radicular sob condições salinas pode ser atribuída à redução da fotossíntese; em condições salinas o número e tamanho das folhas de plantas glicófitas são reduzidos devido à baixa disponibilidade de água, aumento da concentração salina da solução e a toxicidade pela alta concentração de sais no ambiente radicular.
Ao considerar que o mamoeiro é modernamente tolerante (AYERS; WESTCOT, 1999) aos efeitos dos sais e que a irrigação com águas que ofereçam restrições moderadas $(\mathrm{CEa}>1,21 \mathrm{dS}$ $\mathrm{m}^{-1}$ e $\left.\mathrm{CEa}<2,11 \mathrm{dS} \mathrm{m}^{-1}\right)$ ou severas $(\mathrm{CEa}>4 \mathrm{dS}$ $\mathrm{m}^{-1}$ ) pode comprometer a produção de mudas com qualidade para o transplantio. Esses resultados estão de acordo com Cavalcante et al. (2009) ao constatarem superioridade no desenvolvimento radicular de mudas de maracujazeiro amarelo em 
substrato com biofertilizante e irrigadas com águas salinas e também por Mesquita et al. (2010) ao avaliarem o diâmetro da raiz principal de mudas de maracujazeiro amarelo, irrigadas com águas salinas sem e com biofertilizante bovino.

Apesar da expressiva superioridade das mudas de mamão Havaí tratadas com biofertilizante rico em relação aquelas sem o respectivo insumo, observa-se que a área foliar das plantas de mamão foi drasticamente reduzida com o aumento da salinidade das águas de $65,52 \mathrm{~cm}^{2}$ contra 352,72 $\mathrm{cm}^{2}$ na salinidade limiar de $2,12 \mathrm{dS} \mathrm{m}^{-1}$, visto que é no solo sem e com biofertilizante (Figura 5).

Haja vista, nos tratamentos sem biofertilizante e com a elevação do teor salino das águas de 0,5 para $4 \mathrm{dS} \mathrm{m}^{-1}$ provocou perdas de até $272,4 \%$ na biomassa vegetal, ou seja, pode ser limitada tanto pela produção como pelo uso dos fotoassimilados por parte dos meristemas foliares (Figura 5). De acordo com Maas e Hoffman (1977), o efeito acumulativo dos sais no solo faz com que a disponibilidade de água para a cultura diminua à medida que a salinidade aumenta.

Figura 5. Área radicular das mudas de mamoeiro para efeito da salinidade da água no solo sem (---) e com (-) biofertilizante rico. CCA/UFPB, Areia, Brasil-2011.

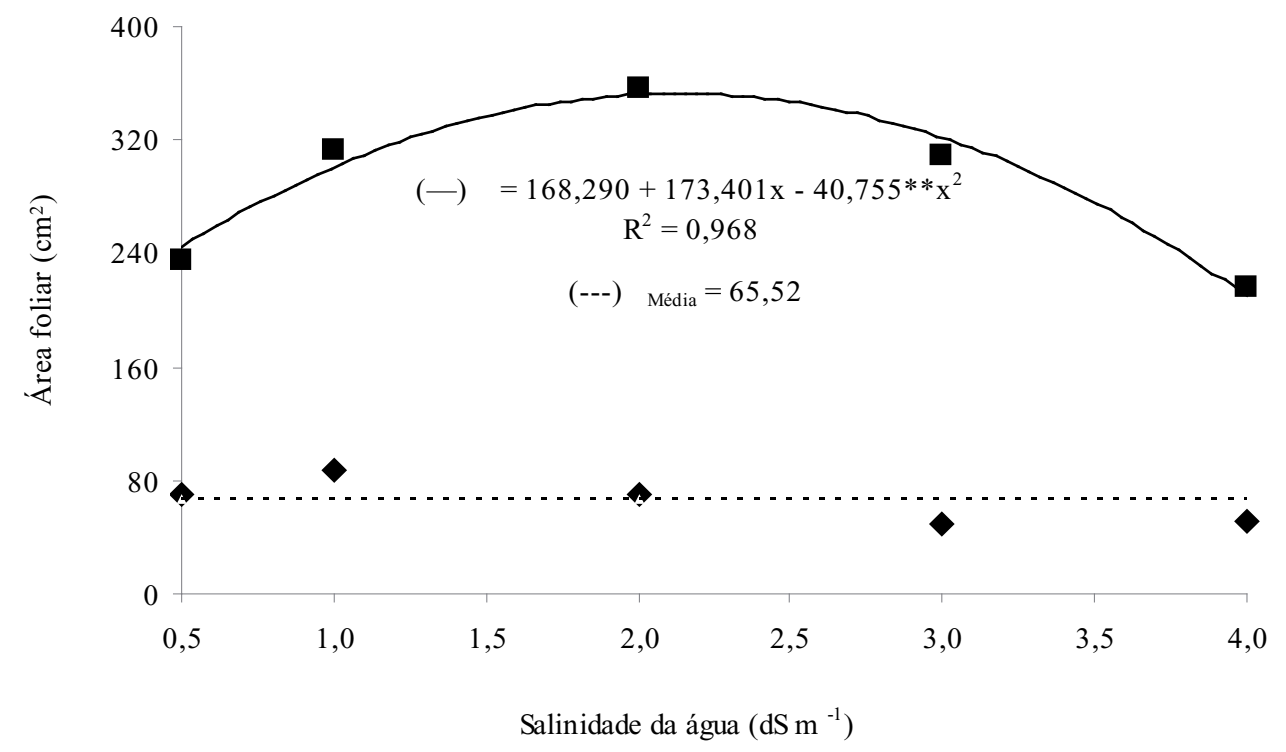

Fonte: Elaboração dos autores.

Essa situação ficou evidente não só na cultura do mamoeiro (Carica papaya L.) e maracujazeiro amarelo (MESQUITA et al., 2010) como também na cultura da pimenta (KAYA et al., 2009) e em tomateiro (ABDEL-LATEF; CHAOXINH., 2011) nessas mesmas condições. Em função disso, uma variedade de mecanismos tem sido proposta para determinar como os microorganismos (micorrizas) amenizam os efeitos do estresse salino sobre as plantas. Por exemplo, a colonização micorrízica pode aumentar aquisição de nutrientes de plantas cultivadas com a alta salinidade (KAYA et al., 2009; HAJIBOLAND et al., 2010).

Esses dados são superiores aos encontrados por Luna Souto et al. (2010), ao estudarem área foliar de mudas de mamoeiro Havaí irrigados com águas salinas e com biofertilizante. Onde esses autores obtiveram $162,35 \mathrm{~cm}^{2}$ de área foliar na salinidade limiar $1,87 \mathrm{dS} \mathrm{m}^{-1}$ aos 90 dias após a emergência de plântulas e por Santos et al. (2010) nas mesmas 
condições conseguiram $160 \mathrm{~cm}^{2}$ na salinidade estimada de $1,87 \mathrm{dS} \mathrm{m}^{-1}$.

Com base na (Figura 6) a área de raiz das plantas de mamão Havaí foi influenciado significativamente pela interação salinidade da água $\mathrm{x}$ biofertilizante e expressa superioridade nos tratamentos com biofertilizante.

Comparativamente às plantas tratadas com biofertilizante, as plantas apresentaram área radicular com valor máximo $103,69 \mathrm{~cm}^{2}$ no caráter salino $0,5 \mathrm{dS} \mathrm{m}^{-1}$ contra $0,61 \mathrm{~cm}^{2}$ na condutividade elétrica estimada de $3,2 \mathrm{dS} \mathrm{m}^{-1}$ nos tratamentos sem o respectivo insumo. A maior expansão radicular das plantas no solo com biofertilizante, em geral é resposta da melhor condição física proporcionada ao substrato pelas substâncias húmicas (LIANG et al., 2005; ABDEL-LATEF; CHAOXINH, 2011), assim como, ao maior acúmulo de solutos orgânicos como carboidratos solúveis e outras substâncias como prolina nas plantas elevando a capacidade de ajustamento osmótico (BAALOUSHA; HEINO; LE COUSTUMER, 2006; SUCRE; SUÁRES, 2011).

A energia gasta pela planta para absorver água em um solo salino é superior àquela para absorver água de uma solução sem sais. Essa redução no desenvolvimento da área foliar em relação ao crescimento radicular diminuiria o uso de água pela planta, permitindo assim uma maior concentração de sais no solo prejudicando as atividades metabólicas das plantas (MUNNS; TESTER, 2008).

Figura 6. Área radicular das mudas de mamoeiro para efeito da salinidade da água no solo sem (---) e com (-) biofertilizante rico. CCA/UFPB, Areia, Brasil-2011.

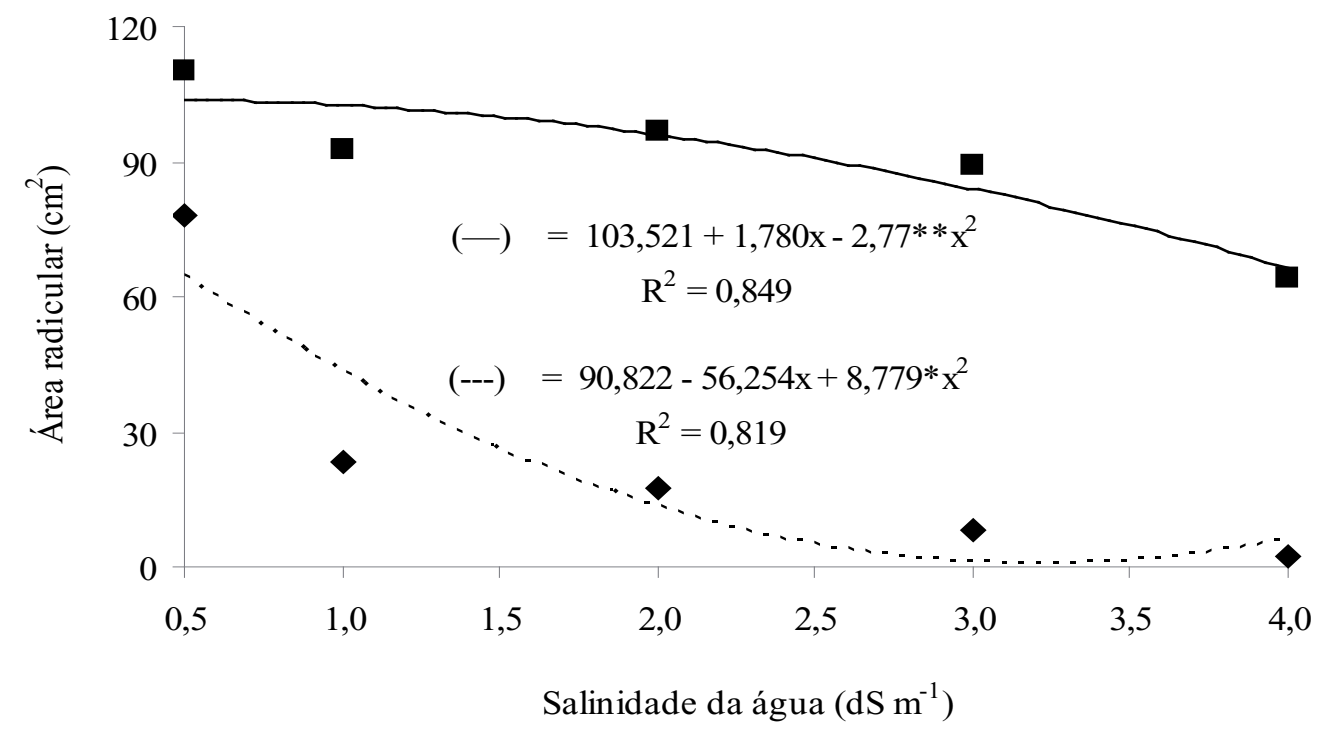

Fonte: Elaboração dos autores.

A massa seca de raízes das plantas de mamão Havaí foi influenciada significativamente pela interação salinidade da água $\mathrm{x}$ biofertilizante e expressa superioridade nos tratamentos com biofertilizante (Figura 7). Na ausência da aplicação do insumo, os dados da massa seca das raízes, não se adequaram a nenhum modelo de regressão, por isso foi representado pela média de 0,078 g planta $^{-1}$. Apesar da expressiva superioridade das mudas de mamão Havaí tratadas com biofertilizante rico em relação tratamentos sem o respectivo insumo, se observa que a matéria seca das raízes aos 90 dias 
após emergência foi drasticamente reduzida com o aumento da salinidade das águas alcançando valor máximo de $1,71 \mathrm{~g}$ planta $^{-1}$ na salinidade limiar de $1,90 \mathrm{dS} \mathrm{m}^{-1}$. Esse decréscimo provocou uma inibição de $267 \%$ entre as fitomassas radiculares das plantas irrigadas com água de 0,5 e $4 \mathrm{dS} \mathrm{m}^{-1}$ (Figura 7).

Comparativamente, os resultados da massa seca de raiz no substrato sem e com biofertilizante para efeito da salinidade da água de irrigação, os valores foram inferiores aos apresentados por Cavalcante et al. (2009) quando avaliaram a biomassa seca das raízes das mudas de maracujazeiro amarelo aos 70 dias após a semeadura, em função das doses de biofertilizante aplicadas no substrato uma semana antes da semeadura e 30 dias após a emergência das plântulas perceberam aumento máximo de 4,86 g planta $^{-1}$ na dose estimada de $10 \%$. Porém, superiores ao encontrados por Cavalcante et al. (2010a) ao estudarem a biomassa de raiz de mamoeiro Havaí, aos 60 dias após a germinação, em função de níveis e fontes de sais da água irrigação conseguido obter maior de 0,56 g planta $^{-1}$ na salinidade estimada de $0,4 \mathrm{dS} \mathrm{m}^{-1}$.

Figura 7. Massa seca de raiz das mudas de mamoeiro para efeito da salinidade da água no solo sem (---) e com (-) biofertilizante rico. CCA/UFPB, Areia, Brasil-2011.

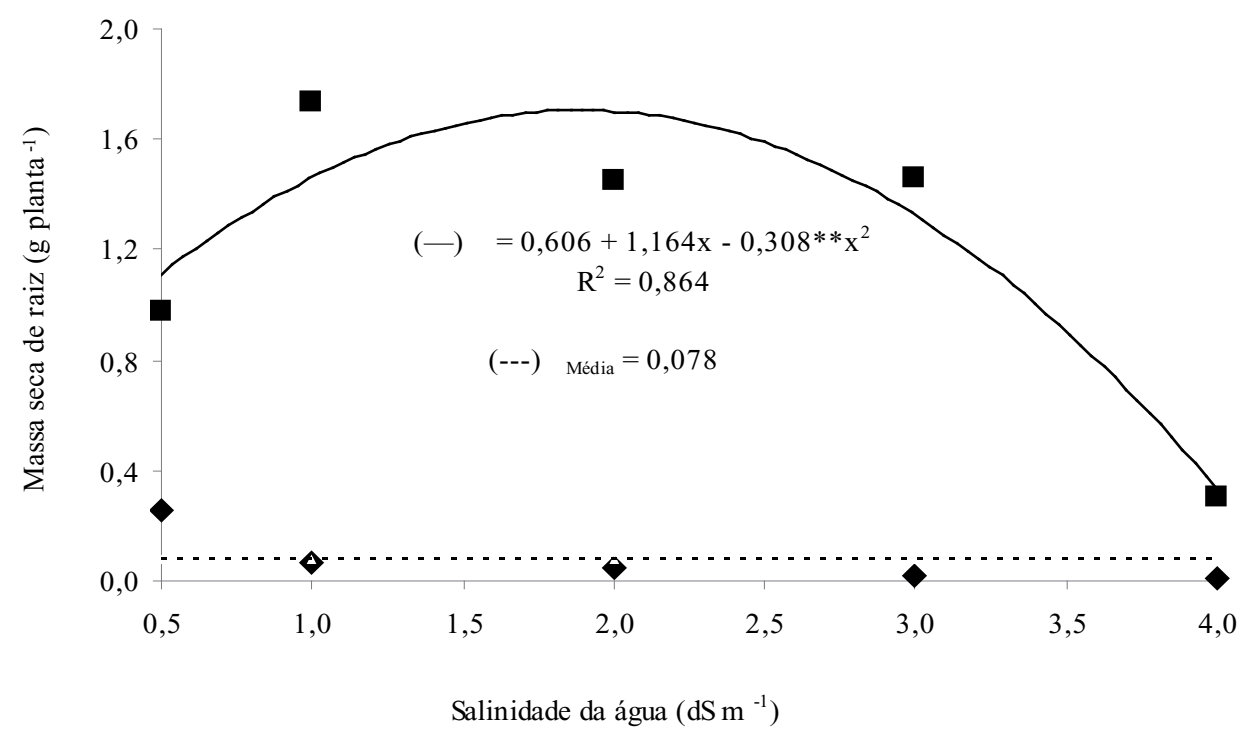

Fonte: Elaboração dos autores.

A massa seca da parte aérea das plantas de mamão Havaí foi influenciada significativamente pela interação salinidade da água x biofertilizante e expressa superioridade nos tratamentos com biofertilizante (Figura 8). Como verificado para massa seca de raízes, a massa seca de parte aérea das plantas de mamoeiro (Caules e folhas), não se ajustou a nenhum modelo matemático, sendo o valor referente aos níveis salinos das águas representados pela média de $0,52 \mathrm{~g}$ planta $^{-1}$ no solo com biofertilizante (Figura 8).
Nos tratamentos com biofertilizante, a elevação do teor salino das águas de 0,5 para $4 \mathrm{dS} \mathrm{m}$ m $^{-1}$ provocou perdas de até $13,15 \%$ no acúmulo de massa seca da parte aérea, aos 90 dias após emergência das plântulas (Figura 8). Na presença do biofertilizante rico a massa seca de parte aérea das mudas de mamão alcançaram valor estremo de 3,73 g planta $^{-1}$ na salinidade estimada sem restrição às atividades metabólicas das plantas de 2,23 dS $\mathrm{m}^{-1}$. Nessas condições, as perdas na acumulação de fitomassa são, na maioria dos casos, provocadas 
pela abscisão e redução da área foliar, em função da senescência precoce pela ação tóxica do excesso de sais na água de irrigação (TAIZ; ZEIGER, 2006; SILVA et al., 2008).

O estimulo à produção de biomassa até a condutividade elétrica máxima de $2,23 \mathrm{dS} \mathrm{m}^{-1}$ pode ser devida á melhoria física e química promovida pelas substâncias húmicas liberadas pelos componentes complexados ou elementos ligantes presentes na composição química do biofertilizante, além de atenuar os efeitos depreciadores ou efeitos diretos da toxicidade dos íons ou efeitos indiretos dos íons salinos presentes no solo causando desequilíbrios osmóticos às plantas (ABDELLATEF, 2010; GARCÍA; ALCÁNTARA; FERNÁNDEZ, 2011). O biofertilizante rico possui uma gama de microrganismos que irão colonizar as raízes diminuindo os efeitos degenerativos dos sais, proporcionando maior alocação de carboidratos para a parte aérea do que para os tecidos da raiz (KAYA et al., 2009; DAS; DANG, 2010; DINESH et al., 2010), inclusive aos efeitos dos fitohômonios e fitoestimulantes contidos no biofertilizante, como as auxinas que induzem o crescimento vegetal (SANTOS; AKIBA, 1996; BORASTE et al., 2009).

Figura 8. Massa seca da parte aérea das mudas de mamoeiro para efeito da salinidade da água no solo sem (---) e com (-) biofertilizante rico. CCA/UFPB, Areia, Brasil-2011.

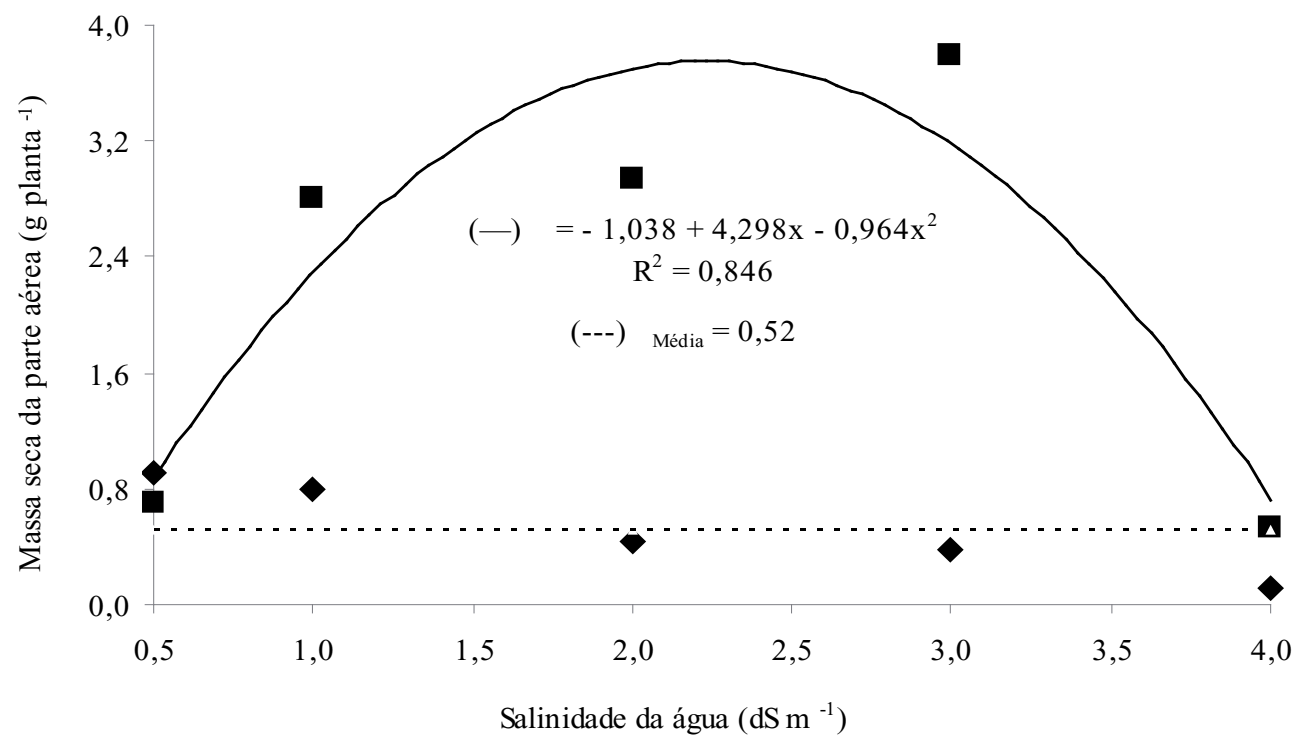

Fonte: Elaboração dos autores.

Estando esses dados se comportando de forma semelhante aos apresentados por Cavalcante et al. (2010a) quando avaliarem biomassa da parte aérea de plantas de mamoeiro Havaí, aos 60 dias após a germinação, em função de níveis e fontes de sais da água irrigação. Os referidos autores, mostraram valores extremos de 2,39 $\mathrm{g}_{\text {planta }}{ }^{-1}$ na salinidade limiar de $0,45 \mathrm{dS} \mathrm{m}^{-1}$.
Estando bem aquém dos encontrados por Galvão et al. (2007) ao verificarem na massa seca parte aérea de mudas de mamão cv. Sunrise, em solo sob diferentes substratos orgânicos, o valor máximo de 1,09 g planta $^{-1}$ com composto orgânico + esterco de boi + casca de arroz carbonizado.

Com base na (Figura 9), os resultados da massa seca total das plantas de mamoeiro, não 
foram significativos estatisticamente para efeito da interação salinidade $\mathrm{x}$ biofertilizante. No entanto, as mudas de mamoeiro obtiveram valores médios de 0,20 e $1,43 \mathrm{~g}_{\text {planta }}{ }^{-1}$ no substrato sem e com biofertilizante rico. Tal fato mostra que o biofertilizante exerce efeitos positivos sobre o crescimento e desenvolvimento das plantas, além de contribuir para a melhoria do solo estimulando a microbiota do solo, produzindo prolina, glicina, ácidos nucléicos e membranas combinados a outros elementos complexados existente na própria composição do biofertilizante resultando em maior ajustamento osmótico (LIANG et al., 2005; BORASTE et al., 2009).

Constata-se que o insumo orgânico promoveu um aumento de $615 \%$ na massa seca total equiparada aos tratamentos que não receberam o insumo orgânico. Esse comportamento está além dos encontrados por Santos et al. (2010) ao avaliarem a massa seca total das plantas de mamoeiro Havaí, irrigadas com águas salinas com biofertilizante bovino. Onde esses autores conseguiram obter valor médio de $0,82 \mathrm{~g} /$ planta aos 90 dias após a emergência das plântulas.

Também estão superiores aos apresentados por Galvão et al. (2007) ao verificarem massa seca total das mudas de mamão cv. Sunrise em solo sob diferentes substratos orgânicos, de forma que esses autores conseguiram obter valor máximo de 1,32 g/ planta com composto orgânico + esterco bovino + casca de arroz carbonizado. Tendências semelhantes foram registradas também por Nunes et al. (2009), Rebequi et al. (2009) e Cavalcante et al. (2010b) ao avaliarem os efeitos do biofertilizante bovino e da irrigação com águas salinas durante o crescimento inicial de noni (Morinda centrifolia), limão cravo (Citrus limonia Osbeck) e de goiabeira Paluma (Psidium guajava).

Figura 9. Massa seca total das mudas de mamão Havaí em substrato na ausência (1) e presença (2) de biofertilizante rico. Médias seguidas por letras iguais na coluna (maiúscula para salinidade e minúscula para biofertilizante) não diferem estatisticamente pelo teste Tukey a 5\% de probabilidade. CCA/UFPB, Areia, Brasil-2011.

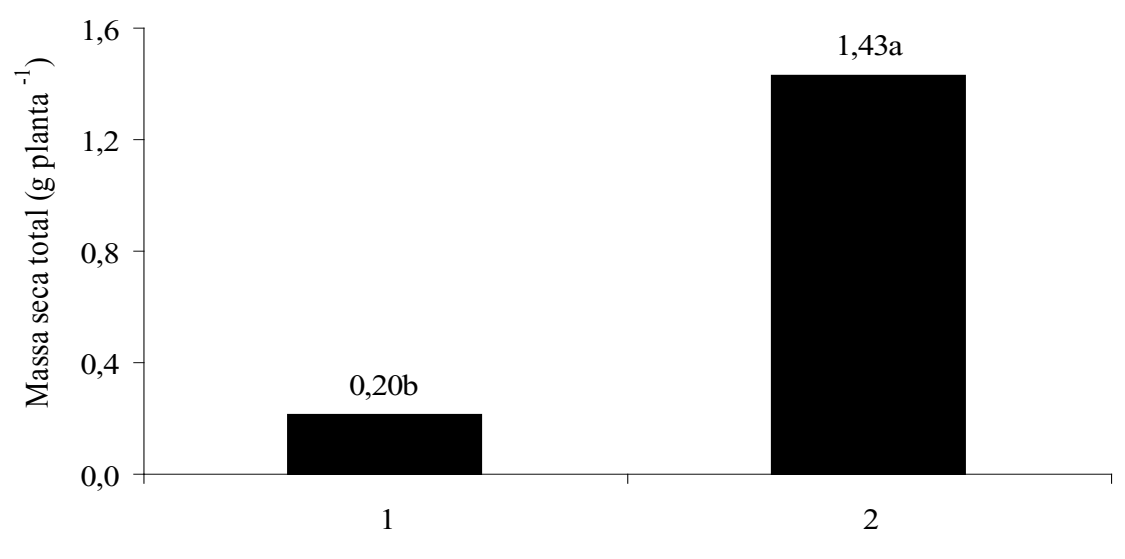

Biofertilizante

Fonte: Elaboração dos autores. 


\section{Conclusões}

O diâmetro do caule e da raiz principal, a área radicular e foliar, a biomassa das raízes e da parte aérea das plantas foram maiores nas plantas cultivadas no solo com o biofertilizante.

A superioridade de todas as variáveis estudadas indica ação positiva do biofertilizante na redução dos efeitos salinos da água de irrigação às plantas.

A salinidade do solo aumentou com a salinidade da água, mas com menor intensidade nos tratamentos com biofertilizante.

\section{Referências}

ABDEL-LATEF, A. A. Changes of antioxidative enzymes in salinity tolerance among different wheat cultivars. Cereal Res. Comm., Egito, v. 38, n. 1, p. 43-55, 2010.

ABDEL-LATEF, A. A. H.; CHAOXINH, H. Effect of arbuscular mycorrhizal fungi on growth, mineral nutrition, antioxidant. Science Horticulture, Egito, v. 127, n. 1, p. 228-233, 2011.

ANUÁRIO BRASILEIRO DE FRUTICULTURA. Gazeta: Santa Cruz do Sul, RS. 2010, 129 p.

ARAÚJO NETO, S. E. de; OLIVEIRA, E. B. de L.; AZEVEDO, J. M. A. de; KUSDRA, J. F.; FERREIRA, R. L. F. Substratos alternativos para produção orgânica de mudas de maracujazeiro-amarelo. In: CONGRESSO BRASILEIRO DE FRUTICULTURA, 18., 2006, Cabo Frio. Anais...Campo dos Goytacazes: UEMA/SBF, 2006. p. 136.

ARDAHANLIOGLU, O.; OZTAS, T.; EVREN, S.; YILMAZ, H.; YILDIRIM, Z. N. Spatial variability of exchangeable sodium, electrical conductivity, soil $\mathrm{pH}$ and boron content in salt-and sodiumaffected areas of the Igdir plain. Journal of Arid Environments, Turquia, v. 54 n. 3, p. 495-503, 2003.

AYERS, R. S.; WESTCOT, D. W. A qualidade da água na agricultura. Tradução por H. R. Gheyi; J. F. de Medeiros; F. A. V. Damasceno. Campina Grande: UFPB, 1999. 153 p. (Estudos FAO: Irrigação e Drenagem, 29, Revisão).

BAALOUSHA, M.; HEINO, M. M.; LE COUSTUMER, B. K. Conformation and size of humic substances: effects of major cation concentration and type, $\mathrm{pH}$, salinity and residence time. Colloids and surfaces. Physicochemical and Engineering Aspects, Amsterdan, v. 222, n. 1-2, p. 48-55, 2006.
BANZATTO, D. A.; KRONKA, S. N. Experimentação agrícola. 4. ed. Jaboticabal: UNESP, 2008. 247 p.

BORASTE, A.; VAMSI, K. K.; JHADAV, A.; KHAIRNAR, Y.; GUPTA, N.; TRIVEDI, S.; PATIL, P.; GUPTA, G.; GUPTA, M.; MUJAPARA, A. K.; JOSHI, B. Biofertilizers: A novel tool for agriculture. International Journal of Microbiology Research, Índia, v. 1, n. 2, p. 23-31, 2009.

BRITO NETO, J. F.; PEREIRA, W. E.; CAVALCANTE, L. F.; ARAÚJO, R. C.; LACERDA, J. S. Produtividade e qualidade de frutos de mamoeiro 'sunrise solo' em função de doses de nitrogênio e boro. Semina: Ciências Agrárias, Londrina, v. 32, n. 1, p. 69-80, 2011.

CAMPOS, V. B.; CAVALCANTE, L. F.; RODOLFO JÚNIOR, F.; SOUSA, G. G. de; MOTA, J. K. de M. Crescimento inicial da mamoneira em resposta à salinidade e biofertilizante bovino. Magistra, Cruz das Almas, v. 21, n. 1, p. 041-047, 2009.

CARLESSO, V. O.; BERBERT, P. A.; SILVA, R. F. da; THIÉBAUT, J. T. L.; OLIVEIRA, M. T. R. Germinação e vigor de sementes de mamão (carica papaya L.) cv. golden secadas em altas temperaturas. Revista Brasileira de Sementes, Rio de Janeiro, v. 31, n. 2, p. 228-235, 2009.

CAVALCANTE, L. F.; CAVALCANTE, I. H. L. Uso de água salina na agricultura. In: CAVALCANTE, L. F.; LIMA, E. M. (Ed.). Algumas frutiferas tropicais e a salinidade. Jaboticabal: FUNEP, cap. 1, 2006. p. 1-17.

CAVALCANTE, L. F.; CORDEIRO, J. C.; NASCIMENTO, J. A. M.; CAVALCANTE, H. L.; DIAS, T. J. Fontes e níveis da salinidade da água na formação de mudas de mamoeiro cv. sunrise solo. Semina: Ciências Agrárias, Londrina, v. 31, p. 1281-1290, 2010a. Suplemento 1.

CAVALCANTE, L. F.; SILVA, G. F.; GHEYI, H. R.; DIAS, T. J.; ALVES, J. C.; COSTA, A. P. M. Crescimento de mudas de maracujazeiro-amarelo em solo salino com esterco bovino líquido fermentado. Revista Brasileira Ciências Agrárias, Recife, v. 4, n. 4, p. 414-420, 2009.

CAVALCANTE, L. F.; VIEIRA, M. S.; SANTOS, A. F.; OLIVEIRA, V. M.; NASCIMENTO, J. A. M. Água salina e esterco bovino líquido na formação de mudas de goiabeira cultivar Paluma. Revista Brasileira de Fruticultura, Jaboticabal, v. 32, n. 1, p. 251-261, 2010 b.

DAS, K.; DANG, R. Influence of biofertilizers on stevioside content in Stevia rebaudiana grown in acidic soil condition. Archives of Applied Science Research, Índia, v. 2, n. 4, p. 44-49, 2010.

DINESH, R.; SRINIVASAN， V.; HAMZA， S.; MANJUSHA, A. Short-term incorporation of organic manures and biofertilizers influences biochemical and 
microbial characteristics of soils under an annual crop [Turmeric (Curcuma longa L.)]. Bioresource Technology, Índia, v. 101, n. 1, p. 4697-4702, 2010.

EL-HENDAWY, S. E.; HU, Y.; YAKOUT, G. M.; AWAD, A. M.; HAFIZ, S. E.; SCHIMIDHALTER, U. Evaluating salt tolerance of wheat genotypes using multiple parameters. Europa Journal Agronomy, Amsterdam, v. 22, n. 1, p. 243-253, 2005.

EMPRESA BRASILEIRA DE PESQUISA AGROPECUÁRIA - EMBRAPA. Centro Nacional de Pesquisa de Solos. Manual de métodos de análise do solo. 2. ed. Rio de Janeiro: Embrapa, 1997. 212 p. (Embrapa-CNPS. Documentos, 1).

FERREIRA, P. A.; MOURA, R. F.; SANTOS, D. B.; FONTES, P. C. R.; MELO, R. F. Efeitos da lixiviação e salinidade da água sobre um solo salinizado cultivado com beterraba. Revista Brasileira de Engenharia Agrícola e Ambiental, Campina Grande, v. 10, n. 3, p. 570-578, 2006.

FERREIRA-SILVA, S. L.; SILVEIRA, J. A. G.; VOIGT, E. L.; SOARES, L. S. P.; VIÉGAS, R. A. Changes in physiological indicators associated with salt tolerance in two contrasting cashew rootstocks. Brazilian Journal of Plant Physiology, Londrina, v. 20, n. 1, p. 51-59, 2008.

FREIRE, J. L. O.; CAVALCANTE, L. F.; REBEQUI, A. M.; DIAS, T. J.; SOUTO, A. G. L. Necessidade hídrica do maracujazeiro-amarelo cultivado sob estresse salino, biofertilização e cobertura do solo. Revista Caatinga, Mossoró, v. 24, n. 1, p. 82-91, 2011.

GALVÃO, O. R.; ARAÚJO NETO, S. E.; SANTOS, F. C. B.; SILVA, S. S. Desempenho de mudas de mamoeiro cv. sunrise solo sob diferentes substratos orgânicos. Revista Caatinga, Mossoró, v. 20, n. 3, p. 144-151, 2007.

GARCÍA, B. L.; ALCÁNTARA, L. P.; FERNÁNDEZ, J. L. M. Soil tillage effects on monovalent cations $\left(\mathrm{Na}^{+}\right.$and $\mathrm{K}^{+}$) in vertisols soil solution. Catena, Espanha, v. 84, n. 1, p. 61-69, 2011.

HAJIBOLAND, R.; ALIASGHARZADEH, A.; LAIEGH, S. F.; POSCHENRIEDER, C. Colonization with arbuscular mycorrhizal fungi improves salinity tolerance of tomato (Solanum lycopersicum L.) plants. Plant Soil, Egito, v. 331, n. 1, p. 313-327, 2010.

INSTITUTO BRASILEIRO DE GEOGRAFIA E ESTATÍSTICA - IBGE. Produção agrícola municipal. 2004. Disponível em: $<$ http://www.ibge.gov.br.>. Acesso em: 30 jun. 2005.

KAYA, C.; ASHRAF, M.; SONMEZ, O.; AYDEMIR, S.; TUNA, A. L.; CULLU, M. A. The influence of arbuscular mycorrhizal colonisation on key growth parameters and fruit yield of pepper plants grown at high salinity. Scientia Horticulturae, Turquia, v. 121, n. 1, p. 1-6, 2009.

LEITE, E. M.; DINIZ, A. A.; CAVALCANTE, L. F.; GHEYI, H. R.; CAMPOS, V. B. Redução da sodicidade em um solo irrigado com a utilização de ácido sulfúrico e gesso agrícola. Caatinga, Mossoró, v. 23, n. 2, p. 110116, 2010.

LIANG, Y. C.; SI, J.; NIKOLIC, M.; PENG, Y.; CHENG, W.; JIANG, Y. Organic manurestimulates biological activity barley growth in soil subject to secondary salinization. Soil biology and biohemestry. Acta Horticulturae, China, v. 37, n. 6, p. 1185-1195, 2005.

LUNA SOUTO, A. G. de; JULIANA, Z. S.; MESQUITA, F. O.; CAVALCANTE, L. F.; NASCIMENTO, J. A. M. de; OLIVEIRA, J. O. Influência da salinidade da água na formação de mudas de mamão Havaí em substrato com biofertilizante bovino. In: CONGRESSO BRASILEIRO DE FRUTICULTURA, 21., 2010, Natal. Anais... Natal: CBF, 2010. p. 1-6.

MAAS, E. V.; HOFFMAN, G. J. Crop salt tolerance current assessment. Journal of Irrigation and Drainage Division, New York, v. 103, n. 2, p. 115-134, 1977.

MAHMOUD, A. A.; MOHAMED, H. F. Impact of Biofertilizers Application on Improving Wheat (Triticum aestivum L.) Resistance to Salinity. Research Journal of Agriculture and Biological Sciences, Campina Grande, v. 4, n. 5, p. 520-528, 2008.

MEDEIROS, R. F.; CAVALCANTE, L. F.; MESQUITA, F. O.; RODRIGUES, R. M.; SOUSA, G. G.; DINIZ, A. A. Crescimento inicial do tomateiro-cereja sob irrigação com águas salinas em solo com biofertilizantes bovino. Revista Brasileira de Engenharia Agrícola e Ambiental, Campina Grande, v. 15, n. 5, p. 505-511, 2011.

MESQUITA, F. O.; CAVALCANTE, L. F.; REBEQUI, A. M.; LIMA NETO, A. J. de; NUNES, J. C.; NASCIMENTO, J. A. M. dos. Produção de mudas de maracujazeiro amarelo em substrato com biofertilizante bovino irrigado com águas salinas. Agropecuária Técnica, Areia, v. 31, n. 2, p. 1-9, 2010.

MORAIS, F. A.; ARAÚJO, F. M. M. C.; MACHADO, A. V.; RICARTE, F. D. N.; SALES JUNIOR, R. Influência da atmosfera modificada sob a vida útil pós-colheita do mamão formosa. Revista Verde, Mossoró, v. 5, n. 4, p. $1-9,2010$.

MUNNS, R.; TESTER, M. Mechanisms of salinity tolerance. Annuario journal Plant Biology, Austrália, v. 1, n. 59, p. 651-681, 2008. 
NUNES, J. C.; CAVALCANTE, L. F.; REBEQUI, A. M.; LIMA NETO, A.; DINIZ, A. A.; SILVA, J. J. M.; BREHM, M. A. S. Formação de mudas de noni sob irrigação com águas salinas biofertilizante bovino no solo. Engenharia Ambiental, Londrina, v. 6, n. 2, p. 451463, 2009.

REBEQUI, A. M.; CAVALCANTE, L. F.; NUNES, J. C. ; DINIZ, A. A.; BREHM, M. A. S.; BECKMANNCAVALANTE, M. Z. Produção de mudas de limão cravo em substrato com biofertilizante bovino irrigado com águas salinas. Revista de Ciências Agrárias, Lisboa, v. 32, n. 1, p. 219-228, 2009.

RICHARDS, L. A. Diagnostico y rehabilitación de suelos salinos y sódicos. México: Departamento de Agricultura de los Estados Unidos de América, 1954. 174 p. (Manual de Agricultura, 60).

RODRIGUES,R.M.;CAVALCANTE,L.F.;MEDEIROS, R. F.; MESQUITA, F. O.; NASCIMENTO, J. R. do; RODRIGUES, R. M. águas salinas e biofertilizante bovino no crescimento inicial do mamoeiro (carica papaya L.) e na salinização do solo. In: CONGRESSO BRASILEIRO DE FRUTICULTURA, 21., 2010, Natal. Anais... Natal: CBF, 2010. p. 1-4.

SANTOS, A. C. V.; AKIBA, F. Biofertilizante líquido: uso correto na agricultura alternativa. Seropédica: UFRRJ, Impr. Univ., 1996. 35 p.

SANTOS, F. C. B. dos; GALVÃO, R. O.; SILVA, S. S. da; ARAÚJO NETO, S. E. de. Produção de mudas de mamoeiro cv. 'Surinse solo' em diferentes substratos orgânicos. Revista Brasileira de Agroecologia, Porto Legre, v. 2, n. 2, p. 1674-1677, 2007.

SANTOS, H. G.; JACOMINE, P. K. T.; ANJOS, L. H. C.; OLIVEIRA, V. A.; OLIVEIRA, J. B.; COELHO, M. R.; LUMBREBAS, J. F.; CUNHA, T. J. F. Sistema brasileiro de classificação de solos. 2. ed. Rio de Janeiro: Embrapa Solos, 2006. 306 p.

SANTOS, J. Z. dos; SANTOS, G. P.; CAVALCANTE, L. F.; LIMA NETO, A. G. dos; MESQUITA, F. O.; LIMA NETO, A. J. de. Formação de mudas de mamão havaí irrigado com água salina e biofertilizante. In: CONGRESSO BRASILEIRO DE FRUTICULTURA, 21., 2010, Natal. Anais... Natal: CBF, 2010. p. 1-5.
SAS Institute. SAS/ESTAT 2003: user's guide: statistics version 9.1 Cary, 2003. 1 CD-ROM.

SHETEAWI, S. A.; TAWFIK, K. M. Interation effect of some biofertilizers and irrigation water regime on mung bean (Vigna radiate) grow the and yield. Applied Sciences Reseach, Cairo, v. 3, n. 3, p. 251-262, 2007.

SILVA, A. B. F.; FERNANDES, P. D.; GHEYI, H. R.; BLANCO, F. F. Growth and yield of guava irrigated with saline water and addition of farmyard manure. Revista Brasileira de Ciências Agrárias, Recife, v. 3, n. 4, p. 354359, 2008.

SILVA, A. L. F. da; BENITES, R. S. P.; ARAÚJO NETO, S. E. de; KUSDRA, J. F.; FERREIRA, R. L. F. Substratos alternativos para produção orgânica de mudas de pimenta-de-cheiro. In: SEMINÁRIO DE INICIAÇÃO DA UFAC, 15., 2006, Rio Branco. Anais... Rio Branco: UFAC, 2006. CD-ROM.

SOUSA, G. B.; CAVALCANTE, L. F.; CAVALCANTE, I. H. L.; BEKMANN-CAVALCANTE, M. Z.; NASCIMENTO, J. A. M. Salinidade do substrato contendo biofertilizante para formação de mudas de maracujazeiro-amarelo irrigado com água salina. Revista Caatinga, Mossoró, v. 21, n. 2, p. 72-180, 2008.

SUCRE, B.; SUÁRES, N. Effect of salinity and PEGinduced water stress on water status, gas exchange, solute accumulation, and leaf growth in Ipomoea pes-caprae. Environmental and Experimental Botany, Venezuela, v. 70, n. 1, p. 192-203, 2011.

TAIZ, L.; ZEIGER, E. Fisiologia vegetal. 4. ed. Porto Alegre: Artmed, 2009. 719 p.

YURTSEVEN, E.; KESMEZ, G. D.; ÜNLÜKARA, A. U. The effects of water salinity and potassium level son yield, fruit quality and water consumption of a native central anatolian tomato species (Lycopersicon esculantum). Agricultural Water Management, Ankara, v. 78, n. 1, p. 128-135, 2005. 